\section{Continentes ou conjugati? Uma análise do dispositivo de sexualidade agostiniano no contexto da Querela Jovinianista}

\author{
'Continentes' or 'conjugati'? An analysis about the Augustine's \\ sexual dispositive in the context of the Jovinianist Controversy
}

Wendell dos Reis Veloso*

Resumo: Este artigo analisa o pensamento de Aurélio Agostinho, bispo de Hipona, no norte da África romana, sobre as sexualidades em dois tratados escritos no início do século V, no contexto da Querela Jovinianista: De bono coniugali e De sancta virginitate. Com o auxílio das reflexões teóricas de Michel Foucault, pretende-se apontar que a tentativa discursiva de positivar o matrimônio, em consórcio com o louvor da virgindade, levou Agostinho a adotar posição ambivalente, de modo que seu posicionamento pode ser entendido como, em parte, anti-reprodutivo e, objetivamente, antisexualidade ativa. Como resultado, a sexualidade reprodutiva concedida indulgentemente se liga ao longo processo histórico de naturalização do que hodiernamente denominamos de heteronormatividade.

\begin{abstract}
This article analyzes the thinking of Augustine, Bishop of Hippo in Northern Roman Africa, on sexualities in two treatises written in the beginning of the fifth century in the context of the Jovinianist Controversy: De Bono Coniugali and De Sancta Virginitate. With the help of the theoretical reflections of Michel Foucault it is pointed out that the bishop's discursive attempt to harmonize marriage with the praise of virginity has led him to adopt an ambivalent position, so that his position can be understood as in part anti-reproductive and, objectively, anti-sexuality active. As a result, the reproductive sexuality granted indulgently is linked to the long historical process of naturalization of what we now call heteronormativity.
\end{abstract}

\section{Palavras-chave:}

Agostinho de Hipona; Querela Jovinianista; Sexualidade.

\section{Keywords:}

Augustine of Hippo; Jovinianist Controversy; Sexuality.

\footnotetext{
* Professor presencial de História Antiga e de História Medieval no Curso de História EAD do consórcio UNIRIO/ CEDERJ/UAB (Polo Resende). Mestre e doutorando em História pela Universidade Federal Rural do Rio de Janeiro, sendo integrante do Grupo de Pesquisa Núcleo Dimensões do Medievo, na Universidade Federal Fluminense, e do Laboratório de Estudos das Relações de Gênero, Masculinidades e Transgêneros (LAbQueer) da UFRRJ.
} 


\section{Introdução}

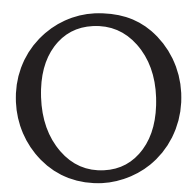

objetivo deste artigo é delinear o posicionamento de Aurélio Agostinho acerca das sexualidades, no contexto do que denominamos historiograficamente de Querela Jovinianista, a partir de dois tratados agostinianos escritos neste período, a saber: as obras De bono coniugali (Os bens do matrimônio) e De sancta virginitate ( $A$ santa virgindade).

O elemento social que norteia a escrita do hiponense é o matrimônio, o qual se encontrava no cerne da disputa teológica aludida no título deste artigo. A expressão querela jovinianista faz referência justamente ao debate teológico e normativo travado em fins do século IV e início do $V$ entre o monge Joviniano, o monge Jerônimo e o bispo católico da cidade de Hipona, no norte da África, Aurélio Agostinho.

Cabe iniciar este texto apontando o que se entende por sexualidade. A definição do sociólogo Anthony Giddens (1993, p. 33), professor emérito de Sociologia da London School, parece adequada para tal: "A sexualidade é uma elaboração social que opera dentro dos campos do poder, e não simplesmente um conjunto de estímulos biológicos que encontram ou não uma liberação direta".

Desta maneira, para o alcance do objetivo traçado, são utilizadas as proposições do pensador francês Michel Foucault em torno do dispositivo de sexualidade. Com isto, intento destacar que o termo sexualidade(s) faz referência não apenas ao ato sexual propriamente dito, mas também aos desejos e às fantasias associadas ao sexo. Como apontam April Harper e Caroline Proctor (2008, p. 2), a intenção dos estudos das sexualidades é a de compreender a maneira como o sexo, para além do coito, era percebido, e como esta percepção incidiu em concepções de normalidade e de desvio. Concepções estas que, no período aqui estudado, são comumente associadas à ortodoxia e à heterodoxia, respectivamente. Tais apontamentos ligam-se ao campo teórico denominado teoria queer, que também ajuda a lançar outros questionamentos sobre as sexualidades.

\section{Pressupostos teóricos: a perspectiva queer}

A teoria queer tem por uma de suas principais características a intencionalidade de por em xeque os dualismos com os quais as sexualidades têm sido observadas. Desta maneira, esta opção teórica me é profícua na medida em que aponta a limitação das categorias binárias - tais como homossexualidade e heterossexualidade no mundo contemporâneo; natural e contra a natureza nos discursos dos séculos IV e V - para abarcar toda a experiência vivida pelos diferentes seres humanos (MUSSKOPF, 2004, p. 181-182). 
À vista disto, pretendo chamar atenção para algo que me escapava. Muitos cientistas sociais afirmam serem as sexualidades humanas um elemento estruturante das organizações sociais. Nestes trabalhos, dentre os quais se encontra a dissertação de minha autoria, defendida em 2014, reconhecem-se os usos das sexualidades como marcadores sociais de grande importância; ${ }^{1}$ entretanto, e sobretudo, torna-se imperioso o reconhecimento de que, em se tratando dos discursos patrísticos do Império Romano cristão, o projeto político da ecclésia é mais do que marcado por elementos sexuais. Ele é, para além disto, o que atualmente denomina-se de heteronormativo.

Tal termo é contemporâneo e faz referência a uma cultura normativa cujo padrão para um relacionamento afetivo/sexual seria aquele entre os seres que nasceram com as genitálias que comumente são associadas ao feminino e ao masculino e, portanto, são lidos socialmente como mulher e homem, respectivamente; tipo de relacionamento este denominado pelas sociedades hodiernas de heterossexual (MUSSKOPF, 2004, p. 180).

A aproximação entre os poderes políticos protocolares do Império Romano no século IV e uma determinada facção cristã, a católica, teria sistematizado e iniciado o processo de propagação em larga envergadura social de um tipo de moralidade que acabaria por ser conhecida como cristã. ${ }^{2}$ Esta teria como uma de suas principais características o processo histórico que Paul Veyne (1990, p. 157-196) definiu como a passagem de uma bissexualidade voltada para o prazer, à qual teria o seu maior interdito no status, para uma sexualidade paulatinamente associada à procriação.

Embora seja inadequado estudar o Império Romano dos três primeiros séculos da nossa era como um paraíso sem interdito algum para o exercício das sexualidades, é inegável que as evidências históricas das quais dispomos apontam que o exercício sexual nesta sociedade é voltado eminentemente para o prazer, o que o inglês Anthony Giddens (1993, p. 9) denomina de sexualidade plástica, uma sexualidade descentralizada e não comprometida com a reprodução.

Como já afirmamos anteriormente, para o alcance do objetivo de identificar como o sexo foi percebido e como esta percepção incidiu em concepções de normalidade e de anormalidade, a proposta de Michel Foucault se mostra capital. $O$ autor da quadrilogia História da Sexualidade defende, ainda no primeiro volume, que é importante se

\footnotetext{
${ }^{1}$ Dentre eles podemos citar os trabalhos de Richard Sennet (2008) e Peter Brown (1990; 2009). Dos trabalhos brasileiros que partem deste pressuposto, dedicam-se ao estudo do pensamento patrístico e podem ser arrolados entre os estudos de gênero, destaco os trabalhos de Regina Bustamante (1990); Sílvia Siqueira (2004); Wendell Veloso (2014b) e Fabiano Coelho (2018).

2 Diferentes especialistas afirmam que o que nós conhecemos como moral cristã, na verdade, é a apropriação cristã de uma moral pagã oriunda do que Paul Veyne chama de paganismo intelectualizado, que surge no Alto Império Romano (MEEKS, 1997; VEYNE, 1990, p. 157-196).
} 
debruçar sobre os discursos e identificar as relações de poder que se articulam no que o pensador denomina de dispositivo de sexualidade, que engendra o que vai se colocar como sexualidade, incluindo aí as práticas e os desejos (FOUCAULT, 1988, p. 85-144). Tal dispositivo, de acordo com Foucault, faz referência ao sexo-história, ao sexo-significação e ao sexo-discurso, muito mais do que ao sexo-natureza, pois, para além do elemento sexual que caracteriza os seres humanos, Michel Foucault (1988, p. 88) argumenta que as sociedades humanas colocam-se "sob o signo do sexo, porém de uma Lógica do sexo, mais do que de uma Física".

Entre os principais elementos constituidores do dispositivo de sexualidade foucaultiano estão: "a relação negativa com as sexualidades", o modo sempre desfavorável com o qual as sexualidades são descritas, especialmente se distantes do padrão heteronormativo; "a instância da regra", "o ciclo da interdição" e "a lógica da censura", às quais, por questão de espaço, podem ser descritas como os mecanismos sociais que visam ao controle dos corpos e das sexualidades, assim como aos discursos que intentam naturalizar estas interdições. Este processo se vale de aspectos jurídicos formais, sistematização de saberes médicos e religiosos, além de outros aspectos, os quais se ligam ao último elemento tratado pelo pensador francês: "a unidade do dispositivo", evidenciando que o poder sobre as sexualidades se exerce de maneira ampla, tanto formal quanto informalmente (FOUCAULT, 1988, p. 93-101).

A partir da leitura da documentação, fica claro que as sexualidades somente são possíveis se pensadas em relação ao matrimônio, à procriação e à castidade. Ou seja, os discursos sobre o matrimônio, a procriação e a vida de modo casto integram o dispositivo de sexualidade que forja o que será outorgado como sexualidade para aqueles sob o jugo das instituições eclesiásticas, sexualidade esta que defendo estar associada ao que se conhece atualmente como heteronormatividade. Cabe aqui relembrarmos que, desde o final do século IV, a facção nicena do cristianismo era a religião oficial do Império Romano, de modo que ser cidadão romano se confundia com ser cristão e, destarte, estar de acordo com a lógica normativa do cristianismo. É a partir destas considerações que proponho a leitura e a análise dos tratados De bono coniugali e De sancta virginitate.

\section{As sexualidades no Império Romano cristão}

Diferentemente do cristianismo, que organizaria a sexualidade em torno da concepção de natureza ligada à noção de verdade, a sociedade romana anterior ao cristianismo institucionalizado, de acordo com Paul Veyne (1990, p. 182), irá tender a 
organizar as sexualidades em torno do status social. Ou seja, a relação dinamizadora das relações sexuais seria a do patrão e a dos seus subordinados.

As evidências de que não importariam como estes subordinados eram lidos socialmente, isto é, se associados aos gêneros masculino e feminino, são muitas: Caio Júlio Cesar, cuja relação com Cleópatra já foi tema até de filmes hollywoodianos, também seria famoso na Antiguidade por ser considerado a esposa de todos os homens e o marido de todas as mulheres; o filósofo grego Plotino, profundo influenciador da teologia patrística, afirmava, sem fazer juízo de valores, que os verdadeiros pensadores deveriam abster-se da beleza dos rapazes e das mulheres; Apuleio, de igual maneira, ao classificar aquilo que seria infame aos cidadãos, não incluiu aí o amor grego; e os exemplos se sucedem, de Catulo, passando por Cícero até Virgílio. Dentre os imperadores, talvez o mais famoso seja Adriano, cujo amante, Antínoo, foi alvo mesmo de um culto oficial após a sua morte, aos 19 anos de idade, sem mencionar a cidade de Antínoopolis, erigida pelo imperador em homenagem ao seu amante. Destaca-se o fato de não haver nenhum registro que faça referência à relação entre Adriano e Antínoo como algo ontologicamente ruim ou negativo (FUNARI, 2006, p. 107; VEYNE, 2008, p. 229-232).

Ao contrário do que comumente se pensa, entretanto, as sexualidades no Mundo Antigo seguiriam rigorosos códigos de conduta, não sendo, portanto, adequada a sua compreensão como um paraíso para as relações homoeróticas, por exemplo. Ao que parece pelas fontes, o grande interdito levaria em consideração dois eixos: homem livre e homem não livre; penetrador e penetrado, sendo que o estatuto de cidadão se daria justamente em torno da posse simbolizada pela penetração. É o penetrar que garantiria a suposta qualidade que seria a virilidade, de modo que um cidadão jamais poderia ser penetrado, ao contrário das mulheres, escravos e crianças, que eram considerados seres inferiores (FUNARI, 2006, p. 107). A grande vergonha estaria, portanto, associada ao fato de colocar-se à disposição do prazer do outro, daí o sexo oral ser um grande tabu sexual do mundo romano (VEYNE, 1990, p. 182).

E sobre o que historiograficamente ficou conhecido como nova moral cristã, Paul Veyne (1990, p. 189), em concordância com Michel Foucault (1988), defende: "a moral cristã existiu, em primeiro lugar, como entidade separada, como moral da sociedade pagã, antes de se agregar à nova religião". O mesmo autor vai argumentar que, a partir de 284, os novos imperadores vão basear sua administração em um corpo de especialistas, ocorrendo o que se denomina de substituição de uma aristocracia senatorial baseada nas relações de parentesco por uma aristocracia de serviço. Como maneira de se diferenciar do antigo grupo senatorial, a nova aristocracia iria se apoiar em um movimento denominado de paganismo intelectualizado, um paganismo de elite marcado, dentre outras coisas, 
pela renúncia sexual e por incentivo às núpcias como alternativa à impossibilidade de renúncia completa.

É esta tendência que será aprofundada, sistematizada e propagada pelos autores cristãos dos séculos IV e V, especialmente ao colocarem no centro de suas argumentações as reflexões paulinas destinadas às comunidades de Corinto (BRUNDAGE, 1990, p. 83).

\section{A Querela Jovinianista}

As obras agostinianas em questão foram produzidas aproximadamente entre os anos de 401 e 412, como parte da resposta à controvérsia jovinianista. Isto por que os tratados De bono coniugali e De sancta virginitate são partes de um mesmo projeto, qual seja, a defesa da identidade católica em meio a uma discussão entre o monge Jerônimo, o bispo Agostinho e o monge Joviniano, e que tem como ponto central as sexualidades.

Joviniano foi um monge que viveu na cidade de Roma em fins do século IV. Durante a sua prática monástica teria difundido a doutrina de acordo com a qual não há diferença alguma entre os casados, ou seja, os conjugati, e os castos e os virgens, os continentes aludidos no título deste artigo. Ou seja, de acordo com os pressupostos jovinianistas, todos os cristãos batizados gozariam de uma vida cristã de mesmo valor (HUNTER, 2006, p. 769). Em palavras de Elizabeth Clark (1986, p. 144): "De acordo com Joviniano, o batismo cristão deixava todas as pessoas em igualdade, fossem elas casadas, viúvas ou virgens; nenhum nível de mérito existiria para diferenciar cristãos com base em suas práticas ascéticas".

Em consonância com esta doutrina, portanto, mesmo as virgens consagradas e os monges seriam incentivados por Joviniano a contrair matrimônio. Tais concepções chegam ao conhecimento do monge Jerônimo, em 392, por meio da viúva Marcela. Esta envia a Jerônimo a obra jovinianista, na qual se encontrava a sistematização de uma ética pró-sexo, em antagonismo a qualquer tipo de ascetismo. Incitado pela solicitação de Marcela para que forumlasse uma resposta, Jerônimo, entre os anos de 392 e 393, escreve o tratado Adversus lovinianum (Contra Joviniano). Neste é afirmada categoricamente a existência de uma hierarquia entre os cristãos batizados, sendo o topo desta hierarquia ocupado pelos cristãos continentes e castos (COELHO, 2014, p. 45-46; 2015, p. 9).

Ainda sobre o pensamento de Jerônimo, Joyce Salisbury (1986) e Peter Brown (1990; 2009) sustentam que, no pensamento do monge oriundo de Estridão, a sexualidade, o matrimônio e a prole seriam consequências diretas do acontecimento mítico da Queda, o pecado original do primeiro casal da narrativa bíblica. Desta maneira, Peter Brown (1990) chama a atenção para a suspeita sob a qual o matrimônio seria colocado. Jerônimo chega 
a defender que, diferentemente das primeiras núpcias, às quais poderiam ser melhor compreendidas por conta da carne, os segundos e terceiros casamentos se aproximariam de um estilo de vida pernicioso, estando inclusive na opinião deste eclesiástico, algumas vezes, a um passo do bordel (BROWN, 1990, p. 309-310). De maneira sintética, não parece absurdo apontar que, para Jerônimo, o único resultado benéfico do casamento seria o de produzir virgens para a Igreja (CLARK, 1986, p. 144).

Para o avanço na compreensão da ética anti-sexo, proclamada por Jerônimo, não se pode obliterar a importância das mulheres para a manutenção e a expansão física e material do cristianismo. Gilvan Ventura da Silva $(2007$, p. 86) afirma que há inúmeros casos de mulheres, casadas e/ou viúvas, que, na qualidade de detentoras de um vasto patrimônio, tornar-se-iam célebres por despender todas, ou quase todas, as suas posses na conservação de igrejas, mosteiros e hospedarias, assim como no auxílio prestado aos monges, dentre outros membros das elites eclesiásticas dos séculos IV e V.

Sendo assim, por um lado, como apontado por Mark Vessey (2006, p. 754), a doutrina propagada por Joviniano se mostrava progressivamente um problema para os grupos eclesiásticos do Império Romano, posto que ao redor deste monge já se aglutinaria um número significativo de fiéis. Tal sucesso talvez fosse oriundo do fato de a pregação jovinianista apresentar uma vida monástica de maior apelo ao homem comum. Por outro lado, tal qual sugere Fabiano Coelho $(2015$, p. 9), os tratados polêmicos penejados por Jerônimo causaram escândalo, sendo considerados deveras radicais e por isso incapazes de surtir efeito contra a doutrina jovinianista, que se popularizava entre os leigos, especialmente os da Península Itálica.

Ainda sobre o assunto, Peter Brown (1990, p. 309) salienta que Jerônimo teria interferido em questões do Império a fim de que a equiparação entre as virgens consagradas da Igreja e os casais unidos por matrimônio, proposta pelo monge Joviniano, sofresse algum tipo de sanção. Da documentação do período, apreende-se que o jovinianismo teria sido condenado em inícios da última década do IV século, em sínodos ocorridos em Roma, sob o bispado de Siríaco e, em Milão, sob o bispado de Ambrósio; além disto, um edito imperial de 398 condenaria Joviniano e seus seguidores a açoites e ao exílio (HUNTER, 2006, p. 769).

\section{As referências em De bono coniugali e De sancta virginitate}

É em meio a estas circunstâncias que o bispo de Hipona escreve os seus tratados polêmicos sobre o matrimônio e a virgindade, inclusive aproveitando a oportunidade para responder aos maniqueus, que acusavam os cristãos de comportamento licencioso, a 
exemplo dos Patriarcas, que teriam tido inúmeras mulheres e concubinas, como apontado pelos seguidores de Mani (Agostinho, De bono coniugali, XXV, 33).

As análises preliminares da primeira destas obras apontam como seu cerne a reflexão acerca do matrimônio e da procriação - única possibilidade de exercício das sexualidades, de acordo com a identidade cristã heteronormativa forjada pelo dispositivo de sexualidade - estar em consonância, ou não, com a natureza, com aquilo que seria próprio dos agrupamentos humanos (Agos., De bono con., II, 2).

Vejamos o trecho retirado do segundo capítulo da obra:

Creio desnecessário discutir agora e dar uma opinião definida sobre a forma como poderia, se não tivesse pecado, dar-se a posteridade dos primeiros homens; quando Deus os abençoou dizendo-Ihes "crescei e multiplicai-vos, e enchei a terra", pois pelo pecado os seus corpos tornaram-se mortais e carnais, e a união carnal não se pode realizar, senão em corpos mortais e carnais (Agos., De bono con., II, 2).

As inquirições sobre como se daria a posteridade dos primeiros homens caso Adão e Eva não tivessem pecado e, portanto, conhecido o sexo é, de certa maneira, uma discussão desnecessária para Agostinho. Reconhecendo a existência de uma discussão sobre o assunto - o debate entre Joviniano e Jerônimo -, Agostinho parte do pressuposto de que o pecado de Adão e de Eva teria tornado os seus corpos mortais e, portanto, tornado necessário o "crescei e multiplicai" ("cum mortis condicionem corpora eorum peccando meruerint nec esse concubitus nisi mortalium corporum possit"). Isto posto, o pecado do primeiro casal do mito bíblico teria tornado impreterível o ato sexual e, por conseguinte, o matrimônio, já que na essência deste estaria a procriação (Agos., De bono con., XIII, 15).

Em oposição à teoria de Jerônimo, Agostinho defende que o matrimônio é um bem, mas não em si mesmo, o sendo apenas em consórcio à realidade decaída da raça humana, como podemos atestar no seguinte trecho: "Por enquanto, afirmamos que, segundo a condição de nascer e morrer, que conhecemos e na qual fomos criados, o matrimônio entre o homem e a mulher é um bem" (Agos., De bono con., III, 3). ${ }^{3}$

Já no início do De sancta virginitate a estratégia de tentar positivar o status matrimonial é evidenciada pelo argumento de que as virgens não deveriam ter pouco apreço aos que teriam sido pais e mães. Entretanto, o caráter dúbio do seu posicionamento, apontado por Elizabeth Clark (1986), mostra-se na assertiva de que esse apreço deveria ocorrer a despeito mesmo de as virgens consagradas permanecerem no "dom mais

${ }^{3}$ No original: "Illud nunc dicimus, secundum istam condicionem nascendi et moriendi, quam novimus, et in qua creati sumus, aliquid boni esse coniugium masculi et feminae" (Agos., De bono con., III, 3). 
eminente que receberam do Senhor" (Agos., De Sancta Virginitate, I, 1). No parágrafo seguinte se encontra:

Pois, se a continência e a virgindade precedem por direito divino ao matrimônio, as virgens não devem se julgar superiores em mérito às pessoas que, pela propagação de filhos em Israel, serviam a Cristo que havia de vir um dia (Agos., De sanc. virg., I, 1).

E o bispo segue, na tentativa de equiparar discursivamente a virgindade e o matrimônio, ao comparar o conjunto de fiéis da Igreja a uma virgem desposada por um único esposo, fazendo uma alusão direta à personagem Maria da mitologia bíblica, ao defender que a Igreja teria como modelo "a mãe de seu esposo e Senhor". Desta maneira indaga: "[...] quão dignos de honra não hão de ser aqueles seus membros que guardam, em sua carne, o que toda a Igreja guarda na fé?" Seguindo nesta mesma linha argumentativa, o bispo afirma que, assim como seria o caso de Maria, a virgindade da Igreja não seria um impeditivo para a fecundidade. Termina o capítulo, entretanto, evidenciando a maior valorização que faz da virgindade ("quanto sanctior est in his membris, ubi virgo est et corpore et spiritu?") frente à impossibilidade de na "vida vivida", na prática, reproduzir o esquema discursivamente apresentado, posto que a geração da prole (e, portanto, a sexualidade ativa e o matrimônio) não pode ser conjugada com a virgindade (Agos., De sanc. virg., II, 2). Nas palavras do hiponense:

Portanto, se a Igreja universal é santa de corpo e de espírito, sem, contudo, ser virgem universalmente pelo corpo, mas só pelo espírito, quanto mais excelente deve ser a santidade naqueles seus membros em que ela é virgem, e pelo corpo e pelo espírito (Agos., De sanc. virg., II, 2).

A impossibilidade do esquema discursivo ser efetivado na vivência é retomada por Agostinho, ao que ele solicita que as virgens não se entristeçam ante a incapacidade de se aliar a virgindade à geração de filhos carnais. Contudo, o autor africano sustenta que aquelas consagradas à virgindade do corpo teriam participação na glória da única santa virgem, a saber, Maria e a geração daquele que seria o Cristo (Agos., De sanc. virg., V, 5).

Já se pode apontar a dificuldade em afirmar que o entendimento do bispo hiponense sobre o matrimônio seria objetivamente positivo. Sendo, na lógica cristã protocolar, a união matrimonial o elemento moralizador e possibilitador do sexo, a primeira característica do dispositivo de sexualidade foucaultiano se evidencia, posto que a defesa de que a concepção de sexualidade no pensamento agostiniano seria positiva é colocada em xeque. 
Ao contrário do que eu tenho defendido neste artigo, importantes estudiosos das sexualidades na Antiguidade argumentaram a favor de uma concepção agostiniana sobre as sexualidades e os corpos que se poderia caracterizar como otimista, desde Joyce Salisbury (1986; 1995), em artigo da segunda metade da década de 80, e o livro do início da década de 1990; passando pelo especialista em Agostinho de Hipona, Peter Brown (2009; 1990), em artigo de 1985, e a sua obra fundamental, Corpo e Sociedade, lançada em fins da década de 1980; até o historiador estadunidense e especialista em sexualidade medieval, James Brundage (1990), com seu manual sobre o tema.

Os autores anglófonos sustentam que Aurélio Agostinho será o sistematizador de um pensamento que vai de encontro à concepção sobre os corpos e as sexualidades formuladas pelos eclesiásticos orientais, assim como também se diferenciaria de autores latinos, que mais teriam reproduzido o paradigma monástico oriental do que dele feito uma espécie de tradução cultural. ${ }^{4}$

Isto fica claro na abordagem que Peter Brown (1990, p. 330) e Joyce Salisbury (1995, p. 69) fazem dos tratados sobre o matrimônio e sobre a virgindade que Agostinho elaborou com o intuito de entrar no debate entre Jerônimo e Joviniano. O autor irlandês afirma que, nestas obras, que datam do início do $V$ século, há a defesa do casamento em harmonia com a castidade e aqueles que se consagram a ela; Joyce Salisbury, por sua vez, assevera que, nestas obras - às quais ela integra, por exemplo, o escrito Contra Fausto -, ocorre o início da defesa da sexualidade, afirmação esta que, de certa maneira, não é absurda, mas que necessita ser problematizada.

Elizabeth Clark (1986, p. 139), por seu turno, publicou seu artigo sobre o assunto no mesmo ano que Joyce Salisbury. O maior diferencial de Clark para Brown e Salisbury está na insistência da primeira nos diferentes contextos de produção das obras agostinianas. Após afirmar que o pensamento agostiniano sobre o que seria essencialmente o casamento é ambivalente, a autora logo assevera que as formulações de Agostinho sobre o matrimônio são todas forjadas em querelas anti-heréticas, evidenciando a ênfase nas circunstâncias do penejar dos tratados (CLARK, 1986, p. 140).

Ainda que o matrimônio seja colocado discursivamente como o moralizador das relações sexuais, Clark (1986, p. 143) chama a atenção para o fato de que a abordagem sempre fora dúbia e vacilante. Isto se evidenciaria mesmo na interpretação assexuada

\footnotetext{
${ }^{4}$ Sobre o paradigma monástico, Peter Brown (2009, p. 270) assim o definiu: "O paradigma monástico colocou um ponto de interrogação no casamento, na sexualidade e até na diferenciação dos sexos. Pois no paraíso Adão e Eva eram seres assexuados. Se perderam seu estado "angélico" de adoradores exclusivos de Deus foi porque, ao menos indiretamente, caíram na sexualidade; e dessa queda na sexualidade começa a deriva de homens e mulheres rumo a um mundo de preocupações próprias dos corações divididos e ligadas ao casamento, ao nascimento de crianças e à dura labuta necessária para alimentar bocas esfaimadas".
} 
do mito da criação, que seria característica do pensamento agostiniano no século IV. Interpretação esta da qual se afastara progressivamente nos seus últimos anos. A estudiosa afirma categoricamente que é somente em seus escritos de 412 em diante que Agostinho formularia a concepção do mito criacionista, sistematizando uma concepção de sexualidade que integraria os planos iniciais da deidade cristã (CLARK, 1986, p. 148). Ou seja, é a partir de De Civitate Dei, obra cuja escrita inicial se dá no início da segunda década do século $V$, que ocorre a sexualização da mitologia cristã sobre o surgimento dos primeiros seres humanos.

Apesar do descrito no parágrafo anterior, entretanto, Elizabeth Clark, fazendo referência ao segundo capítulo da obra, considera a possibilidade de, em De bono coniugali, Agostinho acenar com a viabilidade da interação sexual no Paraíso, ainda que não houvesse pecado, de modo que a reprodução poderia ser entendida como parte dos planos do deus cristão desde o início (CLARK, 1986, p. 145).

Embora seja premente a tentativa de provar discursivamente que o louvor à castidade não põe em xeque o matrimônio e, portanto, o exercício sexual, considero que há uma clara defesa da vida cristã assexuada em De bono coniugali e em De sancta virginitate. E o capítulo aludido por Clark (1986), do primeiro destes tratados, não permite a defesa feita pela autora. Lá se encontra:

Quer consideremos que sem a união carnal, se não tivessem pecado, de algum outro modo teriam filhos por um dom especial do onipotentíssimo Criador, que pôde criar a eles mesmos sem a participação dos pais; que pôde formar a carne de Cristo no seio de uma virgem (Agos., De bono con., II, 2).

A afirmativa de que se eles não tivessem pecado ainda sim teriam procriado ("si non peccassent, habituri essent filios ex munere") não permite a compreensão de que esta progênie ocorreria por meio de atividades sexuais, posto que, em seguida, é lembrado ao público que o primeiro casal da mitologia bíblica da criação teria sido criado e não nascido ("qui potuit etiam ipsos sine parentibus condere"), assim como a deidade cristã teria também se feito carne por meio de uma virgem ("qui potuit carnem Christi in utero virginali formare").

Mais à frente, as ordenanças bíblicas do "crescei e multiplicai-vos" e "povoai a Terra" são associadas à plenitude e à perfeição da vida e do poder ("ut plenitudine et perfectione vitae ac potestatis id fieret"); e também ao desenvolvimento do intelecto e das virtudes ("provectu mentis et copia virtutis intellegatur") (Agos., De bono con., II, 2). Tratase da dessexualização de excertos bíblicos, que poderiam ser entendidos comumente 
em relação às práticas sexuais, posto que o bispo se preocupa em abordar uma outra possibilidade de entendimento deles.

Em outro capítulo, o hiponense apresenta e caracteriza os elementos que poderiam conduzir ao casamento:

Essa exigência imoderada do ato conjugal, que aos casados o Apóstolo não manda imperiosamente, mas Ihes concede indulgentemente: que se unam ainda que não seja por causa da procriação, senão pelos seus depravados instintos se vejam coagidos a tal união, protege o matrimônio contra o adultério e a fornicação (Agos., De bono con., VI, 6).

Ainda que a prole se configure como o cerne do laço matrimonial, este poderia ocorrer por outros motivos, a saber: os impulsos sexuais que são característicos da raça humana. Estes, por sua vez, são descritos como depravados (pravi mores) e conduziriam a um estado de coação que vê o casamento - possível por clemência - como a única saída possível. Em outro trecho é afirmado que o matrimônio é acompanhado de sentimento que se aproxima do suplício, da dor e da desgraça:

Nestes tempos, quantos são os cristãos que, livres do vínculo do matrimônio, e capazes de abster-se de todo comércio carnal, [...] preferem a continência virginal ou viuval, antes de sofrer os tormentos da carne ("tribulationem carnis") inerentes ao matrimônio (Agos., De bono con., XIII, 15).

No segundo tratado agostiniano, em resposta aos monges Joviniano e Jerônimo, Agostinho apresenta uma argumentação que se liga ao que expus anteriormente. Aqui, o bispo de Hipona sustenta que a justificativa apresentada por algumas mulheres, a de que se casariam para fins de gerarem filhos, não compensaria o desperdício de suas virgindades (Agos., De sanc. virg., IX, 9). E segue:

\footnotetext{
Sem dúvida, nos tempos antigos, em que se estava à espera da vinda de Cristo na Carne, era necessária a geração carnal em certa nação em que tudo foi profético. Agora, porém, em que todo o gênero humano e de todas as nações da terra se podem consagrar membros para formar o povo de Deus e para compor a cidade do reino dos céus, não é mais assim. Então, quem tiver capacidade para capturar a santa virgindade a capture $(M t ., 19,12)$ e somente se case quem não puder guardar a continência (1 Cor. 7, 9) (Agos., De sanc. virg., IX, 9).
}

Uma vez que o seu messias já havia encarnado, a geração da prole não poderia ser encarada pelos cristãos como um imperativo. Fazendo referência a outro trecho do tratado já mencionado, deve-se lembrar que o matrimônio seria um impeditivo para a participação na glória de Maria. A escolha do verbo capere, associado à castidade, aponta para a compreensão de que esta não é de tão fácil acesso, posto que se deveria capturá-la, 
aprisioná-la ou confiscá-la (todas estas possibilidades de entendimento do termo), o que permite inferir que o não guardar a continência é fruto de uma espécie de incapacidade, fraqueza e falta de esforço para o entendimento daquilo que seria a vida virginal e as suas supostas benesses.

Assim como afirma que gerar filhos para serem criados nos preceitos do cristianismo não justificaria o que chama de desperdício da virgindade, o bispo também argumenta que a alegação de equidade entre a virgindade e o matrimônio, baseada no fato de que deste nasceriam virgens, não se sustenta, posto que esta é uma característica da natureza ordenada pela deidade cristã. Agostinho ainda insiste que qualquer relação sexual entre homens e mulheres, seja ela "ordenada e honesta" ("ordinato et honesto") ou "torpe e ilícita" ("torpi et illicito"), gera mulheres virgens, mas não virgens consagradas. As primeiras poderiam nascer até mesmo de um estupro, já as segundas nem mesmo do matrimônio (Agos., De sanc. virg., $\mathrm{X}, 10$ ). Tal argumentação tem por objetivo a garantia do monopólio sobre a dinâmica desta virgindade sacralizada, de modo que o hiponense proclama que, se existe uma mãe para as virgens consagradas, esta seria a Igreja ("Si harum quaeritur mater, Ecclesia est") (Agos., De sanc. virg., XII, 11).

Diante de circunstâncias que o obrigaram a emitir sua opinião sobre polêmico assunto para as elites episcopais dos séculos IV e V, Agostinho viu-se compelido a adotar uma posição afastada daquelas radicais defendidas por Joviniano, condenado ao exílio e às penas físicas, e por Jerônimo, especialmente porque colocava em xeque a vida cristã das matronas casadas e até mesmo de viúvas, que teriam sido fundamentais para as instituições cristãs do período.

E mais, considerando que o cristianismo maniqueu possuiria, como uma de suas principais características, a severa moral sexual demandada de seus fiéis, em especial dos membros de sua hierarquia, os chamados eleitos, os quais deveriam se dedicar à perpétua castidade e continência, não se pode esquecer que uma orientação completamente voltada à vida casta poderia incorrer na acusação de maniqueísmo (COSTA, 2003). Tal imputação pesava contra o monge Jerônimo e contra o bispo Agostinho recorrentemente, inclusive por sua prévia ligação a esta vertente do cristianismo por nove anos (CLARK, 1986, p. 146). Talvez por isto, mesmo em um tratado cuja preocupação principal seria o enfrentamento das propostas jovinianistas, consideradas heréticas, e das orientações do monge de Estridão, consideradas um excesso, o bispo hiponense aproveite o De bono coniugali e o De sancta virginitate para responder também aos seus outros inimigos, os cristãos maniqueístas.

Desta maneira, Agostinho defende ser o casamento um bem que se tornaria legal e santo por meio da prole, da fidelidade e do sacramento ("Bonum igitur nuptiarum [...] in 
causa generandi est, et in fide castitas [...], in sanctitate Sacramenti") (Agos., De bono con., $X X I V$, 32). E uma vez que os textos aqui analisados são entendidos como peças de um mesmo projeto, não é de se espantar que tal argumentação se encontre de maneira muito semelhante no tratado subsequente ao De bono coniugali (Agos., De sanc. virg., XII, 12).

Seu posicionamento incongruente, entretanto, se evidencia na afirmação de que o cumprimento do que ele chama de "dever conjugal" não é nenhum pecado ("reddere vero debitum coniugale, nullius est criminis"), mas que a continência seria mais meritória ("illa continentia meriti amplioris est") (Agos., De bono con., VII, 6). Mais à frente, após empreender uma citação neotestamentária atribuída a Paulo, o bispo de Hipona reitera o seu posicionamento:

Estas palavras manifestam, sem deixar dúvidas, que a santidade das inuptas (innuptarum) é mais excelente que a das casadas (nuptarum) e, por conseguinte, aquelas possuem o direito a uma maior recompensa, já que o seu bem é maior e as possibilitam se ocupar apenas em agradar a Deus (Agos., De bono con., Xl, 13).

Verifica-se, portanto, um discurso de antagonização entre as nuptarum e as innuptarum, no qual as segundas são associadas a uma glória maior. A escolha do vocábulo innuptarum ao invés de virgo (virgem) por parte do autor patrístico aponta para a possibilidade de castidade para além da virgindade, posto que os casados também poderiam observar a continência, sem mencionar as viúvas. Sobre este assunto, o hiponense se debruçou e concluiu que, embora os dois modos de guardar a castidade sejam um bem, os não casados ganhariam em excelência se comparados aos casados ("nullo modo dubitandum est meliorem esse castitatem continentiae quam castitatem nuptialem, cum tamen utrumque sit bonum") (Agos., De bono con., XXIII, 28).

Seria possível a transcrição ou a referência a outras passagens dos dois tratados, nas quais esta característica ambivalente e hierarquizante entre continentes e conjugati é apresentada por Agostinho. Entretanto, parece-me que o esquema apresentado por ele nas duas obras é bastante emblemático. Trata-se das categorias que o bispo cria com algumas personagens importantes da mitologia cristã. No segundo dos escritos aqui analisados, ao discorrer sobre o que seria o erro daqueles que elogiavam a virgindade em detrimento do casamento - excerto que pode ser entendido como uma resposta objetiva a Jerônimo -, encontra-se: "Como se o bem de Suzana fosse a humilhação de Maria, ou o bem superior de Maria devesse ser a condenação de Suzana" (Agos., De sanc. virg., XIX, 20). Tal argumentação se liga de modo flagrante ao trecho encontrado no De bono coniugali: "[...] assim também louvamos Susana pela sua castidade conjugal (Dn., 13,22), 
mas preferimos a santa viuvez de Ana $(L C ., 2,36)$ e muito mais a castidade de Maria Virgem (Lc., 1,37)" (Agos., De bono con., VIII, 8).

Há ainda que se mencionar que, de acordo com apontamentos feitos anteriormente neste texto, para o bispo de Hipona, a união carnal somente é possível em corpos mortais e carnais. Atentando-se para o neoplatonismo presente nos escritos agostinianos, há que se ressaltar que a carne encontra-se em oposição ao que seria espiritual, ao que seria divino, elementos estes associados ao Bem platônico e cuja proximidade garantiria a existência e uma maior iminência com a condição de imago Dei, colocada em perigo no episódio mítico do Éden (VELOSO, 2014a).

Conforme as reflexões teóricas de Michel Foucault (1988) nos ajudam a perceber, além da descrição negativa e restritiva das sexualidades, à qual se tenta descrever como sexualidade, identifica-se também, embora não seja o objetivo principal das obras, uma preocupação do autor com esquemas disciplinares que intentam a proteção contra os supostos perigos dos impulsos sexuais, tal como também nos aponta Brundage (1990, p. 86) ser característico da literatura eclesiástica do período. Condena-se o sexo durante o período da gravidez (Agos., De bono con., VI, 5), assim como é asseverado que de nada adiantaria a mulher evitar o casamento a fim de manter-se casta, mas não evitar a luxúria, o orgulho, a curiosidade, a tagarelice, os cabelos frisados, as joias de ouro, as pérolas e os vestidos elegantes (Agos., De bono con., XII, 14). A estes epítetos juntam-se outros, a saber, indiscretas e faladeiras, associadas ao ócio, à desocupação (Agos., De sanc. virg., XXXIII, 34). Já o controle sobre o que se come é associado de maneira mais objetiva à direção dos impulsos sexuais (Agos., De bono con., XVI, 18).

O último dos três elementos elencados por Michel Foucault (1988) como constituintes do dispositivo de sexualidade é a unidade do dispositivo, responsável pelo poder sobre as sexualidades ser exercido de maneira ampla, formal e informalmente. Atuam nesta unidade do dispositivo de sexualidade os discursos que intentam naturalizar as depreciações com as quais as sexualidades são referenciadas, assim como as interdições e as punições para os que tentam e para os que conseguem escapar à regra. Este processo se vale, portanto, de discursividades e ações protocolares ligados a diferentes campos, tais como jurídicos, médicos e religiosos. No contexto da Querela Jovinianista, o episcopado apresenta potencial para atuar de maneira efetiva neste processo.

De acordo com Winrich Löhr (2007, p. 39-40), a África da Antiguidade Tardia foi a região em que o cristianismo mais teria sofrido perseguições, assim como dissidências. A despeito disto, o autor segue argumentando que o território africano tardo-antigo é considerado pelos estudiosos a região mais cristianizada da parte ocidental do Império 
Romano, pois durante o quarto século a maioria da população romanizada teria aderido ao cristianismo, ainda que de maneira apenas superficial.

A organização eclesiástica da Igreja africana se dava em seis províncias: Tripolitânia; Bizacena; África Proconsular, cuja metrópole era Cartago; Numídia; Mauritânia Setifiana; e Mauritânia Cesariana, esta mais refratária ao credo cristão. Aos bispos mais antigos caberia a presidência dos sínodos locais, e ao bispo de Cartago - que tinha o primado da Igreja africana -, costumeiramente, a dos concílios gerais (LÖHR, 2007, p. 40). Nenhuma outra região do Império cristão teria uma Igreja tão organizada quanto à africana. Evidência disto seria o número de bispos existentes, que desde o século III não possuía comparação com nenhuma outra região. No auge das disputas cristológicas, este número chegaria próximo ao de setecentos bispos (LEONE, 2007, p. 243-244). E o poder deles, em grande parte, se originaria do contexto de combate à dissidência religiosa, tal como a Querela Jovinianista, uma vez que este conflito marcaria a interseção entre a Igreja, a sociedade e o poder (DRAKE, 2007, p. 417).

Desde o período em que o Império Romano esteve sob o poder de Constantino, e este favoreceu a religião cristã, os bispos ganharam paulatino poder, a ponto de rivalizar, e às vezes até mesmo suplantar, as elites tradicionais. Inclusive, a partir deste período, especialmente no Ocidente, bispos teriam passado a assumir funções civis que nem as elites locais e nem os administradores imperiais puderam dar conta (DRAKE, 2007, p. 410). Raymond Van Dam (2007, p. 343) chega a defender que a patronagem de Constantino no século IV, assim como a dos imperadores subsequentes, transformou o papel social do bispo de maneiras completamente imprevistas. Acerca das funções civis citadas, Constantino e seus sucessores teriam rapidamente envolvido os bispos em tais questões, responsabilizando-os por resolver os conflitos das comunidades religiosas das quais seriam os responsáveis (DAM, 2007, p. 358). Não se pode deixar de mencionar também que o poder econômico destes homens parece ter sido de igual significância, pois não é sem propósito a tentativa de censura - identificada seja nas atas conciliares ou no Código Teodosiano - àqueles eclesiásticos envolvidos em atividades comerciais e administração de terras (LEONE, 2007, p. 238).

Há também elementos intelectuais a serem considerados. Peter Brown (1992; 2008), em suas argumentações sobre o poder do bispo no mundo tardo-antigo, destaca que, antes de tudo, a princípio, os bispos já fariam parte de uma elite intelectual, de modo que não seria segredo algum que parte do prestígio social adquirido pelos bispos seria legitimado por serem bons retóricos (BROWN, 1992, p. 72-75). Este inclusive seria um dos motivos pelos quais, segundo Brown (2008, p. 172), Agostinho fora considerado para o cargo de bispo da cidade de Hipona. 
Bispos e os clérigos subordinados a eles dividiriam o exercício da autoridade na cidade, produzindo maneiras alternativas para o controle dos habitantes destas regiões. $O$ bispo cristão torna-se, portanto, uma pessoa digna de reverência. Este ainda se destacaria como o ponto de contato entre os indivíduos proeminentes nas comunidades cristãs e o governo imperial (BROWN, 1992, p. 77). A proeminência dos bispos seria tamanha, como argumenta Brown (1992, p. 103 e ss), que, na última década do século IV, a figura dos eclesiásticos seria fundamental para o controle da multidão e, portanto, para a manutenção da paz.

Durante a Antiguidade Tardia, os bispos paulatinamente estenderiam seus domínios para a sociedade romana em geral. O envolvimento contundente destes homens pouco a pouco transformaria a aplicação da justiça, a extensão da caridade, a celebração de cerimônias municipais - agora transformadas em manifestações da espiritualidade cristã -, dentre outras mudanças; todos os aspectos da vida cotidiana, das cortes do Império e dos reinos aos mais pobres, a vida de todos deveria ser mensurada a partir da doutrina cristã ortodoxa (DAM, 2007, p. 361). É de acordo com estas reflexões que as "recomendações" do bispo de Hipona devem ser entendidas, proposições estas que incidiam sobre todas as esferas da vida, evidenciando que o seu exercício de poder ocorreria de modo amplo.

\section{Conclusão}

O ponto de vista positivo sobre as sexualidades no pensamento agostiniano, portanto, não se sustenta frente à análise da documentação. Deve-se atentar para o fato de que, para o hiponense, o matrimônio - e, portanto, a sexualidade - seria aceitável apenas diante da realidade supostamente decaída da humanidade, não fazendo, por conseguinte, parte dos planos divinos.

Para além disto, as relações matrimoniais seriam, como enfatizado pelo hiponense, entre masculi et feminae, o que coloca em evidência o não incentivo às práticas sexuais e, por conseguinte, aos desejos entre os seres humanos com a mesma genitália. E mesmo entre os conjugati os desejos são descritos como pravi mores e como tribulationem carnis. Ou seja, comojá mencionado, insisto que se trata da passagem de uma sexualidade plástica, organizada majoritariamente em torno do prazer, para uma sexualidade flagrantemente estruturada a partir da procriação, mas que, sobretudo, incentiva a continentia, ao associála a um meriti amplioris. Sendo assim, não me parece absurdo tipificar a concepção agostiniana sobre as sexualidades no contexto da Querela Jovinianista, em certa medida como anti-reprodutiva e certamente como anti-sexualidade ativa. 
Isto posto, diante do alegado perigo das sexualidades, há comportamentos descritos como naturais e outros como não naturais, como o sexo com a mulher grávida, as práticas sexuais dos homens mencionados por Paulo no livro de Romanos, dentre outras (Agos., De bono con., X, 11). Trata-se do discurso que intenta a naturalização de certas práticas e a condenação de outras, discursos estes fundamentais para o processo de unidade do dispositivo de sexualidade descrito por Foucault (1988).

Uma vez que as núpcias são descritas por Agostinho como a única maneira legítima de trazer descendência ao mundo, de modo ordinato et honesto (Agos., De bono con., XVII, 19), e a procriação seria a única maneira realmente legítima de se exercer a sexualidade, de acordo com a lógica cristã ortodoxa apresentada por Agostinho, os tratados De bono coniugali e De sancta virginitate mostram-se ínclitos integrantes do dispositivo de sexualidade heteronormativo do bispo Agostinho de Hipona, ainda que se reconheça o caráter ambivalente de seu pensamento. Em outras palavras, integram, portanto, um projeto, um empenho, uma tentativa de franco controle das relações sexuais e sociais, que está ligado ao longo processo de naturalização do que denominamos hodiernamente como heteronormatividade - uma vez que, de acordo com uma lógica cisgênera, a procriação somente é possível por meio da interação de material biológico dos seres lidos socialmente como homem e como mulher - em antagonismo à sexualidade plástica que caracterizava as comunidades romanas.

\section{Referências}

\section{Documentação textual}

SAN AGUSTIN. Obras de San Agustin. Madrid: Católica, 1963. t. XII.

SANTO AGOSTINHO. Dos bens do matrimônio. A santa virgindade. São Paulo: Paulus, 2001. v. 25.

\section{Obras de apoio}

BROWN, P. Antiguidade Tardia. In: VEYNE, P. (Org.). História da vida privada: do Império Romano ao Ano Mil. São Paulo: Companhia das Letras, 2009, p. 213-284. v. 1. BROWN, P. Santo Agostinho: uma biografia. Rio de Janeiro: Record, 2008. BROWN, P. Power and persuation in Late Antiquity: towards a Christian Empire. Wisconsin: The University of Wisconsin Press, 1992. 
BROWN, P. Corpo e sociedade: o homem, a mulher e a renúncia sexual no início do cristianismo. Rio de Janeiro: Jorge Zahar, 1990.

BRUNDAGE, J. Law, sex, and Christian society in Medieval Europe. London: The University of Chicago Press, 1990.

BUSTAMANTE, R. M. da C. O casamento e a esposa: a visão de Agostinho de Hipona. Dissertação (Mestrado em História) - Programa de Pós-Graduação em História Social da Universidade Federal do Rio de Janeiro, Rio de Janeiro, 1990.

CLARK, E. A. "Adam's only companion": Augustine and the early Christian debate on marriage. Recherches Augustiniennes et Patristiques, n. 21, p. 139-162, 1986.

COELHO, F. de S. As matronas da Antiguidade cristã: um estudo comparado das representações de gênero nas obras de Jerônimo e Agostinho (380-420 E. C.). Tese (Doutorado em História) - Programa de Pós-Graduação em História Comparada da Universidade Federal do Rio de Janeiro, Rio de Janeiro, 2018.

COELHO, F. de S. Cristianismo, sexualidade e poder: um estudo comparado da condição dos casados em textos de Agostinho e Jerônimo. Revista Jesus Histórico, v. 8, p. 8-22, 2015.

COELHO, F. de S. O monge Jerônimo e o bispo Agostinho em torno da controvérsia religiosa Jovinianista. Revista Jesus Histórico. v. 13, p. 40-52, 2014.

COSTA, M. R. N. Maniqueísmo: história, filosofia e religião. Rio de Janeiro: Vozes, 2003.

DAM, R. V. Bishops and society. In: CASIDAY, A.; NORRIS, F. W. (Ed.). Constantine to c. 600. Cambridge: Cambridge University Press, 2007, p. 343-366.

DRAKE, H. A. The Church, society and political power. In: CASIDAY, A.; NORRIS, F. W. (Ed.). Constantine to c. 600. Cambridge: Cambridge University Press, 2007, p. 403-428.

FOUCAULT, M. História da sexualidade: a vontade de saber. Rio de Janeiro: Graal, 1988. V. 1.

FUNARI, P. P. Grécia e Roma. São Paulo: Contexto, 2006.

GIDDENS, A. A transformação da intimidade: sexualidade, amor e erotismo nas sociedades modernas. São Paulo: Editora da Universidade Estadual Paulista, 1993.

HARPER, A.; PROCTOR, C. Introduction. In: HARPER, A.; PROCTOR, C. (Ed.). Medieval sexuality: a casebook. New York: Routledge, 2008, p. 1-4.

HUNTER, D. G. Joviniano. In: FITZGERALD, A. (Dir.) Diccionario de San Augustín. Burgos: Monte Carmelo, 2006, p. 769-770.

LEONE, A. Christianity and paganism: North Africa. In: CASIDAY, A.; NORRIS, F. W. (Ed.). Constantine to c. 600. Cambridge: Cambridge University Press, 2007, p. 231-247.

LÖHR, W. Western Christianities. In: CASIDAY, A.; NORRIS, F. W. (Ed.). Constantine to c. 600. Cambridge: Cambridge University Press, 2007, p. 9-51. 
MEEKS, W. As origens da moralidade cristã: os dois primeiros séculos. São Paulo: Paulus, 1997.

MUSSKOPF, A. S. Queer: teoria, hermenêutica e corporeidade. In: TRASFERETTI, J. (Org.). Teologia e sexualidade: um ensaio contra a exclusão moral. São Paulo: Átomo, 2004, p. 181-182.

SALISBURY, J. E. Pais da Igreja, virgens independentes. São Paulo: Página Aberta, 1995.

SALISBURY, J. E. The Latin doctors of the Church on sexuality. Journal of Medieval History, V. 12, n. 4, p. 279-289, 1986.

SENNET, R. Carne e pedra: o corpo e a cidade na Civilização Ocidental. Rio de Janeiro: Bestbolso, 2008.

SILVA, G. V. da. Ascetismo, gênero e poder no Baixo Império Romano: Paládio de Helenópolis e o status das devotas cristãs. História, v. 26, n. 1, p. 82-97, 2007.

SIQUEIRA, S. M. A. A mulher na visão de Tertuliano, Jerônimo e Agostinho (séc. II-V d.C.). Tese (Doutorado em História) - Programa de Pós-Graduação em História da Universidade Estadual Paulista, Assis, 2004.

VELOSO, W. dos R. O regramento sexual na primeira Idade Média a partir da análise do matrimônio no dispositivo de sexualidade Agostiniano. As referências em Dos Bens do Matrimônio (século V). In: TEIXEIRA, I. S.; BARREIRO, C. N.; GONÇALVES, G. da S. (Org.). Idade Média: exercício de pesquisa. São Leopoldo: Oikos, 2017, p. 11-22.

VELOSO, W. dos R. Apontamentos sobre a tradução cultural do neoplatonismo operada por Agostinho de Hipona na Antiguidade Tardia (c. 386-426). Roda da Fortuna, v. 3, n. 1, p. 110-130, 2014a.

VELOSO, W. dos R. Humanidade e sexualidade na proposta de identidade cristã de Agostinho de Hipona em Confissões. Dissertação (Mestrado em História) - Programa de PósGraduação em História da Universidade Federal Rural do Rio de Janeiro, Seropédica, 2014b.

VESSEY, M. Jerónimo. In: FITZGERALD, A. (Dir.) Diccionario de San Augustín. Burgos: Monte Carmelo, 2006, p. 751-755.

VEYNE, P. Sexo e poder em Roma. Rio de Janeiro: Civilização Brasileira, 2008.

VEYNE, P. A sociedade romana. Lisboa: Edições 70, 1990.

WOODWARD, K. Identidade e diferença: uma introdução teórica e conceitual. In: SILVA, T.

T. da (Org.). Identidade e diferença: a perspectiva dos estudos culturais. Petrópolis: Vozes, 2000, p. 7-72. 